Tropical Journal of Pharmaceutical Research March 2014; 13 (3): 475-483

ISSN: $1596-5996$ (print); 1596-9827 (electronic)

(C) Pharmacotherapy Group, Faculty of Pharmacy, University of Benin, Benin City, 300001 Nigeria.

All rights reserved.

Available online at http://www.tjpr.org

Review Article

http://dx.doi.org/10.4314/tjpr.v13i3.24

\title{
Photoprotective Effect of Tea and its Extracts against Ultraviolet Radiation-Induced Skin Disorders
}

\author{
Na-Na Li ${ }^{1}$, Li Deng ${ }^{1}$, Li-Ping Xiang ${ }^{2}$ and Yue-Rong Liang ${ }^{1 *}$ \\ ${ }^{1}$ Zhejiang University Tea Research Institute, Hangzhou, 310058, ${ }^{2}$ Guizhou Tea and Tea Products Quality Supervision and \\ Inspection Center, Zunyi 563100, China
}

*For correspondence: Email: yrliang@zju.edu.cn; Tel: +86 571 88982704; Fax: +86 57188982704

Received: 28 December 2013

Revised accepted: 18 February 2014

\begin{abstract}
Ultraviolet (UV) exposure induces photodamage of skin. It is a matter of concern that the level of UV radiation reaching the earth surface is increasing as a result of depletion of the stratospheric ozone, and climate change. It is urgently necessary to develop strategies to protect the skin from UV-induced injuries. Tea extracts are gaining increasing attention as a supplement in skin care products. However, the factors contributing to the photoprotective effects of tea extracts have not been systematically defined and conflicting results about the effect of tea extracts on photodamage have been reported. In this paper, the literature dealing with the use of tea and its extracts for the prevention of photodamage to the skin as well as the photoprotective effects of tea and its extracts have been highlighted. The potential chemopreventive agents in tea include catechins, caffeine, polysaccharides, apigenin and luteolin which inhibit, reverse or retard the process of the skin photodamage via their sunscreen and antioxidant properties, regulation of signal transduction pathway and gene expression, alleviation of DNA damage, and modulation immunological function are also presented. Existing gaps in this research field include incomplete clarity of photochemopreventive mechanism of tea, the adverse or side effects of tea extracts owing to residues or impurity and the instability of the functional components of tea during storage.
\end{abstract}

Keywords: Camellia sinensis; Photoageing, Antioxidant, Tea extracts, Sunburn, DNA damage; Immunological modulation; Gene expression.

Tropical Journal of Pharmaceutical Research is indexed by Science Citation Index (SciSearch), Scopus, International Pharmaceutical Abstract, Chemical Abstracts, Embase, Index Copernicus, EBSCO, African Index Medicus, JournalSeek, Journal Citation Reports/Science Edition, Directory of Open Access Journals (DOAJ), African Journal Online, Bioline International, Open-J-Gate and Pharmacy Abstracts

\section{INTRODUCTION}

The solar ultraviolet (UV) radiation reaching the earth's surface is increasing because of depletion of the ozone layer. Chronic solar UV radiation to mammalian skin induces a number of biological responses resulting in the development of erythema, edema, sunburn cell, hyperplastic response, photoageing and skin cancer. UV radiation is considered to be a major factor causing skin cancer and other skin and eye diseases [1]. Ultraviolet consists of UVA (320$400 \mathrm{~nm})$, UVB (280-320 nm) and UVC (200-280 $\mathrm{nm}$ ). Overdose of UVA can cause acceleration of skin ageing, and promote photodermatosis and phototoxic reactions, which is a possible carcinogen. Overdose of UV-B can cause acute chronic reactions and damages such as skin reddening or sunburn, increase risks of melanoma, eye damage, and even DNA damage 
in case of high dosage [2]. UVC is intercepted by ozone layer and most of it cannot reach to the earth surface [3]. It is necessary to develop a proper mean to protect human skin and eyes from both UVA and UVB radiation damages.

Experiments in vivo and in vitro show that green tea polyphenols (GTPs) enhanced intracellular antioxidant defense and promoted the down regulation of proapoptotic genes, and they could be used to fight against the dysfunction induced by UV radiation. The major components of GTPs are catechins including (-)-epigallocatechin gallate (EGCG), (-)-epicatechin gallate (ECG), ()-epigallocatechin (EGC) and (-)-epicatechin (EC). The research advances in antiinflammatory, antioxidant and anti-carcinogenic effects of GTPs against UVA/B irradiation were reviewed in the present paper.

\section{ANTI-PHOTOCARCINOGENIC EFFECTS}

Chronic oral feeding of GTPs $(0.1 \% \mathrm{w} / \mathrm{v})$ in female $\mathrm{SKH}-1$ hairless mice resulted in significantly $(p<0.01)$ lower tumor yield (percent of animals with tumors and number of tumors per mouse) induced by UVB as compared to animals receiving normal drinking water. Topical application of GTPs before UVB irradiation also afforded protection against photocarcinogenesis; however, the protective response was lower than that observed by oral feeding of GTPs in drinking water [4]. Record and Dreosti [5] confirmed that oral administration of black tea inhibited the formation of UV-induced skin tumors in hairless mice, in a dose-dependent manner and even when it was consumed with milk, the growth inhibition of UV-related skin tumors was observed. However, the mice consuming tea with $10 \%$ whole milk had $30 \%$ fewer papillomas, 50 $\%$ fewer tumors, and $55 \%$ smaller lesions than the control mice consuming water. Mice consuming tea alone had fewer papillomas and tumors than mice consuming tea with milk. Consumption of either green or black tea resulted in significantly fewer skin papillomas and tumors induced by UVA+B light. Record and Dreosti [6] observed that black tea provided better protection against UVB-induced tumors than green tea.

EGCG is the most abundant functional component in tea. Molecular modification of EGCG improved its bioactivity. Osanai et al found that O-acetylated (-)-EGCG analogs possessing a $p-\mathrm{NH}_{2}$ or $p$-NHBoc (Boc; tertbutoxycarbonyl) D-ring (5 and 7) acted as novel tumor cellular proteasome inhibitors and apoptosis inducers with potency similar to natural EGCG and EGCG peracetate [7].
Studies on anti-photocarcinogenic effect of GTPs showed that oral administration of GTPs inhibited UVB-induced cancers by affecting several biomarkers involved in UV-carcinogenesis, including inhibition of angiogenic factors and recruitment of cytotoxic $\mathrm{T}$ cells in the tumor microenvironment. Test showed that oral administration of GTPs reduced UVB-induced tumor incidence (35\%), tumor multiplicity (63\%), and tumor growth (55\%). The GTPs-UVB group had reduced expression of the matrix metalloproteinases (MMP)-2 and MMP-9, which play crucial roles in tumor growth and metastasis, and enhanced expression of tissue inhibitor of MMP in the tumors compared with the control mice that were treated with UVB alone. The GTPs-UVB group also had reduced expressions of CD31 and vascular endothelial growth factor, which are essential for angiogenesis, and inhibited expression of proliferating cell nuclear antigen in the tumors compared with the UVB group[8].

The anti-photocarcinogenic effect of green tea is considered to act via its antioxidant activity and regulation of proto-oncogene proteins c-fos and P53. EGCG $(10-50 \mu \mathrm{M})$ afforded protection against the oxidative stress of UVA radiation $\left(100-500 \mathrm{KJ} / \mathrm{m}^{2}\right)$ in terms of biological endpoints relevant to carcinogenesis [9].Treatment of psoralen plus UVA induced accumulation of c-fos and P53. However, oral administration of $0.4 \%$ and $0.8 \%$ green tea extract (GTE) before psoralen plus UVA treatment inhibited the c-fos protein accumulation by $18.5 \%$ and $46.2 \%$ ( $p<$ $0.05)$ respectively, and the P53 protein accumulation by $26.1 \%$ and $54.3 \%(p<0.05)$ respectively. Oral administration of $0.4 \%$ and 0.8 $\%$ GTE $1 \mathrm{~d}$ after treatment of psoralen plus UVA treatment was effective in reducing inflammatory responses induced by psoralen plus UVA [10].

\section{ATTENUATION OF SKIN SUNBURN}

GTE produced absorbance at 290-320 nm wavelength range and its sun protection factor (SPF) was 18.10 $\pm 0.05[11]$. Histologically, UVB irradiation induced thinning of living skin equivalents (LSEs) epidermis, whereas EGCG treatment led to thickening of the epidermis, resulting in protection of LSEs against damage and breakdown caused by UVB exposure [12].GTPs protected cells from UVB damage through its attenuation of mitochondria dysfunction [13-14]. Participants treated with a combination regimen of topical and oral green tea showed histological improvement in elastic tissue content. Green tea polyphenols have been postulated to protect human skin from the cutaneous signs of photoageing [15]. Topical 
application of white tea offered protection against detrimental effects of UVA and UVB on cutaneous immunity. It was considered that both green tea and white tea were potential photoprotective agents that might be used in conjunction with established methods of sun protection [15]. Regular intake of green tea component EGCG strengthened the skin's tolerance by increasing minimal erythema dose (MED) and thus prevented UV-induced perturbation of epidermal barrier function and skin damage [16]. Experiments showed that GTE provided substantial photoprotective effects against UVA/B damages [17], based on the examination of skin barrier damage (TEWL), erythema, histological alterations and sunburn cell formation induced by UVA/B irradiation. EGCG and ECG polyphenolic fractions were most efficient at inhibiting erythema, whereas EGC and EC had little effect.

In addition to GTPs, caffeine and tea polysaccharides (TPS) offered the activity of attenuating skin sunburn. There was study revealing that combined application of EGCG with caffeine showed synergistic effect of UV protection [18]. Higher purity TPS had good moisture absorption and retention abilities but little promoting effect on fibroblasts proliferation. GTPs protected skin against UV rays and enhanced proliferation of fibroblast cells significantly and had good tyrosinase inhibitory effects [19]. However, the effects of green tea extract depended on the application method [20].

The skin sunburn attenuating effect of GTE is considered to be related to its activities of antioxidation, inhibiting the decrease of dermal collagen and preventing from DNA damage. Studies using guinea pigs, hairless mice and human dermal fibroblast cultures showed that EGCG-treatment lipid significantly reduced peroxidation. The amount of lipid peroxides produced in the $1 \%$ EGCG aqueous solution treatment was significantly lower than that of water control after UVA and UVB irradiation. EGCG treatment also significantly reduced UVBinduced erythema and UVA-induced skin damage (roughness and sagginess) by inhibiting the decrease of dermal collagen in hairless mouse skin. There was test showing that EGCG treatment blocked the UV-induced increase of collagenase mRNA expression level in fibroblast culture. The nuclear transcription factors NF-kB and AP-1 binding activities were also inhibited by EGCG treatment [21]. Histological examination showed that the skin treated with GTE had less sunburn cells and GTE protected epidermal Langerhans cells from UV damage by reducing the DNA damage [22].

\section{IMMUNOLOGICAL MODULATION}

Exposure of skin to UV radiation can cause diverse biological effects such as inflammation, alteration in cutaneous immune cells and impairment of contact hypersensitivity (CHS) responses. There were in vivo observations showing that GTPs are photoprotective, and can be used as pharmacological agents for the prevention of solar UVB light-induced skin disorders associated with immune suppression [23]. Laboratory tests showed that oral feeding or topical application of GTPs afforded protection against UVB induced immunosuppression and cutaneous inflammatory responses in $\mathrm{C} 3 \mathrm{H}$ mice. The topical application of GTPs or EGCG prior to exposure to UVB protected against UVB-induced local and systemic immune suppression in laboratory animals. Topical application of GTPs (1 - $6 \mathrm{mg}$ /animal), $30 \mathrm{~min}$ prior to or $30 \mathrm{~min}$ after exposure to a single dose of UVB $\left(2 \mathrm{~kJ} / \mathrm{m}^{2}\right)$ resulted in significant protection against local (25 - $90 \%$ ) and systemic suppression (23-95\%) of $\mathrm{CHS}$ and inflammation in mouse dorsal skin (70 - $80 \%$ ). These protective effects were dosedependent. Among the four major epicatechin derivatives present in GTPs, EGCG was found to be the most effective in affording protection against UVB-caused CHS and inflammatory responses [24]. Cyclobutane pyrimidine dimers (CPD) are considered to be mediators of UVBinduced immune suppression and skin cancer induction. Studies on human skin showed that GTPs prevented penetration of UV radiation in human skin by reducing CPD in the reticular dermis.

Interleukin-10 (IL-10) is an anti-inflammatory cytokine, while IL-12 plays an important role in the activities of natural killer cells and $T$ lymphocytes. IL-12 mediates enhancement of the cytotoxic activity of NK cells. UVB radiation induces expression of IL-10 but suppresses expression of IL-12. The preventive effect of EGCG on UV-induced immunosuppression is considered to be mediated by $\mathrm{IL}-10$ and IL-12. There were studies showing that EGCG treatment resulted in reduction of the UVBinduced IL-10 in skin and in draining lymph nodes, and an elevated amount of $\mathrm{IL}-12$ in draining lymph nodes. Topical treatment with EGCG prevented UV-induced suppression of CHS in wild-type (WT) mice but did not prevent it in IL-12 knockout mice. Injection of anti-IL-12 monoclonal antibody to WT mice blocked the preventive effect of EGCG on UV-induced immunosuppression [25].

Macrophages and neutrophils are associated with induction of UVB-induced suppression of 
CHS responses and CD11b is a cell surface marker for activated macrophages and neutrophils. EGCG treatment of mouse skin inhibited UVB-induced infiltration of CD11b1 cells. Topical application of EGCG before UVB exposure reduced the number of $\mathrm{CD} 11 \mathrm{~b}$ +monocytes/macrophages and neutrophils infiltrating into skin inflammatory lesions, which are considered to be responsible for creating the UV-induced immunosuppressive state. It was proposed that EGCG protected against UVBinduced immunosuppression and tolerance induced by: (1) blocking UVB induced infiltration of CD11b + cells into the skin; (2)reducing IL-10 production in skin and in draining lymph nodes (DLN); (3) markedly increasing IL-12 production in DLN [26].

\section{ALLEVIATION OF DNA DAMAGE}

DNA damage is a response of UV-induced photoageing, which results in skin inflammation, photoageing, and photocarcinogenesis. Pyrimidine dimers are molecular lesions formed from thymine or cytosine bases in DNA via photochemical reactions. UV light induces the formation of covalent linkages by reactions localized on the $\mathrm{C}=\mathrm{C}$ double bonds. Cyclobutane pyrimidine dimers (CPDs) are common UV products. A CPD contains a four membered ring arising from the coupling of the $\mathrm{C}=\mathrm{C}$ double bonds of pyrimidines. Such dimers interfere with base pairing during DNA replication, leading to mutations. UVB induced CPDs. Treatment of human skin with varying doses of GTPs (1-4 $\mathrm{mg} / 2.5 \mathrm{~cm}^{2}$ of skin area) before a single dose of UVB exposure (4 MED) decreased the formation of UVB-induced CPDs dose-dependently in both epidermis and dermis [27].

IL-12 was shown to induce DNA repair. It is considered that the reduction of UV-induced cell death by GTPs is mediated via IL-12. KB cells and normal human keratinocytes were exposed to GTPs $5 \mathrm{~h}$ before and after UVB and the test showed that GTPs treatment reduced UVBinduced apoptosis. However, the cell death reduction was almost completely reversed upon addition of an anti-IL-12-antibody. The test confirmed that GTPs induced the secretion of IL12 in keratinocytes $[25,28]$. It was presumed proposed that topical application or oral administration of green tea through drinking water of mice prevented UVB-induced skin tumor development through rapid repair of DNA induced by IL-12 [29].

Flavonoid luteolin is one of tea components with antioxidative activity in addition to catechins. Spectrophotometric measurements revealed that
UV transmission of luteolin below $370 \mathrm{~nm}$ was $<10 \%$.In human skin, luteolin effectively reduced the formation of UVB-induced CPDs. The test of free radical scavenging activity showed that the half-maximal effective concentration (EC50) of luteolin $(12 \mu \mathrm{g} / \mathrm{ml})$ was comparable to those of Trolox $(25 \mu \mathrm{g} / \mathrm{ml})$ and N-acetylcysteine (32 $\mu \mathrm{g} / \mathrm{ml}$ ) in the cellfree DPPH assay system. However, luteolin (EC50 $3 \mathrm{\mu g} / \mathrm{ml}$ ) was much more effective compared to Trolox (EC50 12 $\mu \mathrm{g} / \mathrm{ml}$ ) and $\mathrm{N}$-acetylcysteine (EC50 $847 \mu \mathrm{g} / \mathrm{ml}$ ) in the H2DCFDA assay performed with UVBirradiated keratinocytes. Luteolin was also confirmed to be effective in inhibiting both UVBinduced skin erythema and the upregulation of cyclooxygenase-2 and prostaglandin E2 production in human skin via interference with the MAPK pathway [30;31].

\section{ANTIOXIDATION}

Anti-oxidants have attracted a lot of interest on account of their function to protect the skin from oxidative stress induced by UV radiation. UVA/B damage to skin keratinocytes in vitro is similar to that for reactive oxygen species (ROS) and that GTPs protects against UVA/B-induced cytotoxicity by inhibiting lipid peroxidation and apoptosis. There was study showing that UVA or ROS increased the release of plasma enzyme lactate dehydrogenase ( LDH) and increased lipid peroxidation production (malondialdehyde, MDA), but decreased the activity of glutathione peroxidase (GSH-Px) [32]. UVA or ROS decreased the proliferative index $(\mathrm{PI})$, and blocked the cell growth in the $S / G 2$ phase, leading to an increase in the percentage of apoptosis in primary keratinocytes. Tests showed that GTPs stabilized and protected cell membranes from ROS or UVA damages and modified the UVA or ROS-induced changes in PI and apoptosis via inhibiting the release of LDH, lowering MDA levels, and increasing GSH-Px activity. A formulation containing tannaseconverted green tea extract (FTGE) was effective in protecting skin from UVB photodamage. Significant $(p<0.05)$ prevention of the reduced form of glutathione (GSH) depletion and significant $(p<0.05)$ decreases in thiobarbituric acid-reactive substance levels were observed in mice treated with FTGE [33].

Antioxidant activity of GTPs varied with the structure of polyphenol molecules. EGCG showed the highest antioxidant activity, followed by GCG, EGC and EC in a decreasing order. EGCG showed significantly stronger antioxidative activity than $\alpha$-tocopherol at the later oxidation stage $(p<0.05)$ due to the higher stability of EGCG [34]. Experiment showed that 
catechol derivatives of aminopyrazine were more active than EGCG in reducing cell mortality. EGCG decreased the level of matrix metalloprotienases (MMPs) production and increased tissue inhibitor TIMP-1 expression level [35]. EGCG was proved to be much more effective in ROS-related conditions than retinoic acid (AR)[36]. Additive synergistic effect of antioxidant activity was observed when green tea extract was applied with ascorbic acid[11]. It was revealed that $0.001 \% \mathrm{w} / \mathrm{v}$ of GTPs alone, and in combination with $0.1 \mathrm{mM}$ caffeine, inhibited the upregulation of $\mathrm{H}_{2} \mathrm{O}_{2}$-generated free radicals and 4-hydroxy-2-nonenal (HNE) in human skin fibroblasts in vitro, but caffeine alone showed limited antioxidant properties [37].

The infiltrating leukocytes are considered to be the major source of generation of ROS [38]. EGCG inhibited UV-induced infiltration of inflammatory leukocytes, particularly CD11 ${ }^{+}$ cells (a surface marker of monocytes/macrophages and neutrophils), into the skin, which are considered to be the major producers of ROS [23].Topical application of EGCG (3 $\mathrm{mg} / 2.5 \mathrm{~cm}^{2}$ ) before UVB (4 MED) exposure to human skin significantly blocked UVB-induced infiltration of leukocytes and reduced myeloperoxidase activity.

GTPs increased activities of antioxidases under UV stress conditions. Dietary supplementation with tea catechin could protect epidermal cells against UVB-induced damage by modulating antioxidant enzyme activities. Experiment showed that the superoxide dismutase (SOD) and catalase (CAT) activities of regular diet (RD) group BALB/c mice decreased after UVB irradiation, while those of the $2 \%$ catechinsupplemented diet (2CSD) and the $4 \%$ catechinsupplemented diet (4CSD) groups increased immediately after irradiation and then decreased $(p<0.05)$ [39]. The GPx activities of the 4CSD and the 2CSD groups increased immediately after UVB irradiation, but that of the RD group decreased. A single UV exposure of 4 MED to human skin increased catalase activity by 109 $145 \%$ and lowered glutathione peroxidase (GPX) activity (36 - $54 \%$ ) and total glutathione (GSH) level (13 -36 \%). Pretreatment with EGCG was found to restore the UV-induced decrease in GSH level and afforded protection to the antioxidant enzyme GPx [40].

The c-Jun NH2-terminal kinase (JNK) pathway plays an anti-apoptotic role. There was study revealing that UVB irradiation increased intracellular ROS in ARPE19 cells, resulting in apoptosis, accompanying with decrease in the phosphorylation of JNK1 [41]. Inhibition of JNK with a specific inhibitor augmented this apoptosis, and anisomycin (an activator of JNK) attenuated this apoptosis. EGCG reduced the ROS generation and apoptosis, and also partially blocked the decreased phosphorylation of JNK1 and c-Jun by UVB irradiation. When keratinocytes were photodamaged, ECG could act as a free radical scavenger by inhibiting cell membrane lipid peroxidation and $\mathrm{H}_{2} \mathrm{O}_{2}$ generation [42].

The deleterious effects of excessive release of nitric oxide (NO) have been implicated in the tissue damage and inflammation. Hepatocytes activated with 12-O-tetradecanoyl phorbol 13acetate (TPA, $25 \pm 200 \mathrm{nM}$ ) released $\mathrm{NO}$ in a concentration- and time-dependent manner. GTPs were effective in inhibiting TPA-induced NO generation by $90 \%$ [43]. It was confirmed that application of EGCG (1 $\mathrm{mg} / \mathrm{cm}^{2}$ skin) before a single UV exposure of 4 MED markedly decreased UV-induced production of nitric oxide $(30-100 \%)$ in both epidermis and dermis in a time-dependent manner [40].

\section{REGULATION OF GENE EXPRESSION}

The photo-protective mechanisms of EGCG on UVB-induced skin damage were shown to decrease UVB-induced cell cytotoxicity and apoptosis and to inhibit the mRNA expressions of apoptosis-regulatory gene (such as p53 and p21) and proto-oncogene c-fos gene [44]. EGCG inhibited and down-regulated the UVB-induced activation and translocation of nuclear factor kappa B (NF-kB), expression of inducible nitric oxide synthase (iNOS) mRNA and generation of NO respectively, suggesting that EGCG may play a protective role from UVB-induced skin damage[45]. Tea contains flavonoids apigenin and luteolin, which are confirmed to inhibit ROS production in HaCaT cells exposed to UVA irradiation. Pre-treatment of $\mathrm{HaCaT}$ cells with apigenin and luteolin inhibited UVA-induced production of the collagenase matrix metalloproteinase (MMP)-1. They could suppress UVA-induced expression of c-Jun and c-Fos and the phosphorylation of three MAP kinases, upstream modulators of AP-1. Tea catechins at levels 250 - $1000 \mathrm{mg} / \mathrm{L}$ screened off UV-B, resulting in less expression of chalcone synthase gene [46]. Tests on volunteers showed that UV radiation induced cutaneous erythema, over expression of cytokeratins (CK) 5/6, CK16, MMP2. MMP-9, and depletion of CD1a+ Langerhans cells (LCs). GTE conferred significant protection against the photoageing and photoimmunologyrelated biological events [47]. 
Catechin prevented UVB-induced human keratinocyte death via inhibition of JNK phosphorylation[48], as well as mitogen-activated protein kinase (MAPK) pathway and NF-kB pathway [49]. Treatment of the normal human epidermal keratinocytes (NHEK) with EGCG (10$40 \mu \mathrm{M})$ for $24 \mathrm{~h}$ resulted in a significant inhibition of UVB $\left(40 \mathrm{~mJ} / \mathrm{cm}^{2}\right)$-mediated degradation and phosphorylation of $\mathrm{I}_{k} \mathrm{Ba}$ and activation of MAPK and IKKa, in a dose-dependent manner. Modulation of the NF-kB pathway plays a critical role in a variety of physiological functions and is involved in inflammation and development of cancer. EGCG protected against the adverse effects of UV radiation via modulations in NF-kB pathway [49]. GTPs protected RPE cells from UVB damage through its increase in the survivin gene expression [14,50,51]. Immunohistochemically, the expressions of p53, Fas and 8hydroxy-deoxyguanosine (8-OHdG) are markers of apoptosis. Test showed that EGCG treatment reduced the levels of UVB-induced apoptotic markers in the LSEs [12].

\section{EXISTING GAPS}

The molecular mechanism of photochemopreventive effects of tea is incompletely understood [49], and there were conflicting results about the photoprotective effect of tea components. There was a study showing that the application method of EGCG influenced its photoprotective efficacy. The photoprotective effect of EGCG was observed when it was applied topically before UVA exposure, but no benefit was detected when it was applied after UV exposure [20]. Oral administration of green tea polyphenols (GTP) in drinking water (d.w.) significantly prevented single or multiple UVB irradiation-induced depletion of antioxidant enzymes, oxidative stress, but its photoprotective efficacy was lesser than that of topical treatments of GTP. The less photoprotective efficacy of GTP by oral administration in comparison with topical application might be due to its less bioavailability in skin target cells [52]. The absorption mechanism of tea components by human or animal has not been fully understood. It was considered that the gastrointestinal environment and epithelial transport process could affect the molecular modification and biological activity of orally ingested tea components. Chromatographic study showed that some compounds in the crude tea extracts were either not transported across a tested cell monolayer or they were metabolized during passage through the cells. Chemical modification or degradation of tea chemicals were token place when they were exposed to gastrointestinal conditions. The crude tea extracts exhibited reduced antimicrobial activity after exposure to simulated gastric fluid, while no antimicrobial activity was detected after exposure to simulated intestinal fluid [53]. Basic studies should be designed to further reveal the absorption and photoprotection mechanism of tea components so as to provide theoretical guidance for the development of appropriate application methods.

Adverse events including excess gas, upset stomach, nausea, heartburn, stomach ache, abdominal pain, dizziness, headache, and muscle pain were observed during a 4-week oral administration of EGCG extracted from green tea [54]. These might be related to chemical residues in the extracted products. Cyclic oligomers residues were detected in tea catechins isolated by polyamide- 6 column [55]. There are many kinds of chemicals in tea extracts such as catechins, caffeine and theanine, and various chemicals have different effects on UV radiation. Topical application of caffeine to the dorsal skin of SKH-1 mice immediately after UVB irradiation enhanced UVB-induced apoptosis of sunburn cells and increases in caspase- 3 enzyme activity in the epidermis [56]. These suggest that green chemical method should be developed to isolate and purify functional components from tea to avoid the adverse effects from the chemical residues and the unwanted compounds.

Stability of tea functional components such as catechins incorporated into the skin care products has influence on their photoprotective effect. The incorporation of green tea extract into gelatin films enhanced the DPPH diphenyl-picryl hydrazide) radical scavenging activity and reducing power. However, DPPH radical scavenging activity and reducing power decreased during its storage [57]. It was observed that browning took place during storage of skin cream supplemented with green tea catechins or EGCG. The instability of tea extracts is normally induced by degradation and oxidation of tea catechins. Development of techniques to stabilize tea components will be a hot issue in this research direction.

\section{CONCLUSION}

Excessive exposure of the skin to solar radiation, particularly UVA/B components, is responsible for skin cancers and photoageing. Much progress on photoprotection of tea has been made, showing that tea or GTE has the potential to protect the skin against the adverse effects of UVA/B radiation. The photoprotective agents in tea and tea extract include catechins, caffeine, polysaccharides, apigenin and luteolin (Table 1). They play crucial role in photoprotection via 
Table 1: Potential chemopreventive agents in tea against UV-induced damage

\begin{tabular}{|c|c|c|c|}
\hline Component & Type of tea & Physiological function. & Ref no. \\
\hline $\begin{array}{l}\text { Tea polyphenols } \\
\text { including catechins }\end{array}$ & $\begin{array}{l}\text { Green tea and } \\
\text { white tea }\end{array}$ & $\begin{array}{l}\text { 1. Protection against photocarcinogenesis; } \\
\text { 2. Activation of cytotoxic T cells and inhibition of } \\
\text { angiogenesis in tumors; } \\
\text { 3. Inhibiting UVA-induced erythema; } \\
\text { 4. Attenuates mitochondrion-mediated apoptosis; } \\
\text { 5. Damaged DNA repair; } \\
\text { 6. Prevents UV-induced CD1a+ cells and generation of } \\
\text { 8-OHdG. }\end{array}$ & $\begin{array}{l}4,5,8,10, \\
13,14,16, \\
23,24,27, \\
28\end{array}$ \\
\hline $\begin{array}{l}\text { Theaflavins } \\
\text { Thearubigins }\end{array}$ & Black tea & Protection against UVB-induced Tumors. & 6 \\
\hline $\begin{array}{l}\text { Epigallocatechin-3- } \\
\text { gallate (EGCG) }\end{array}$ & Green tea & $\begin{array}{l}\text { 1. Proteasome inhibitor and cancer cell apoptosis } \\
\text { inducer; } \\
\text { 2. Antioxidant; } \\
\text { 3. Thickening epidermis; } \\
\text { 4. Reduces UVB-induced phosphorylation of JNK and } \\
\text { 538 MAPK; } \\
\text { 6. Immunosuppression; } \\
\text { 6. Reduces UVB-induced inflammatory. }\end{array}$ & $\begin{array}{l}7,9,12,26 \\
38\end{array}$ \\
\hline Polysaccharides & $\begin{array}{l}\text { Green tea and } \\
\text { oolong tea }\end{array}$ & Inhibits tyrosinase & 19 \\
\hline Luteolin & Green tea & Antioxidant & 31 \\
\hline
\end{tabular}

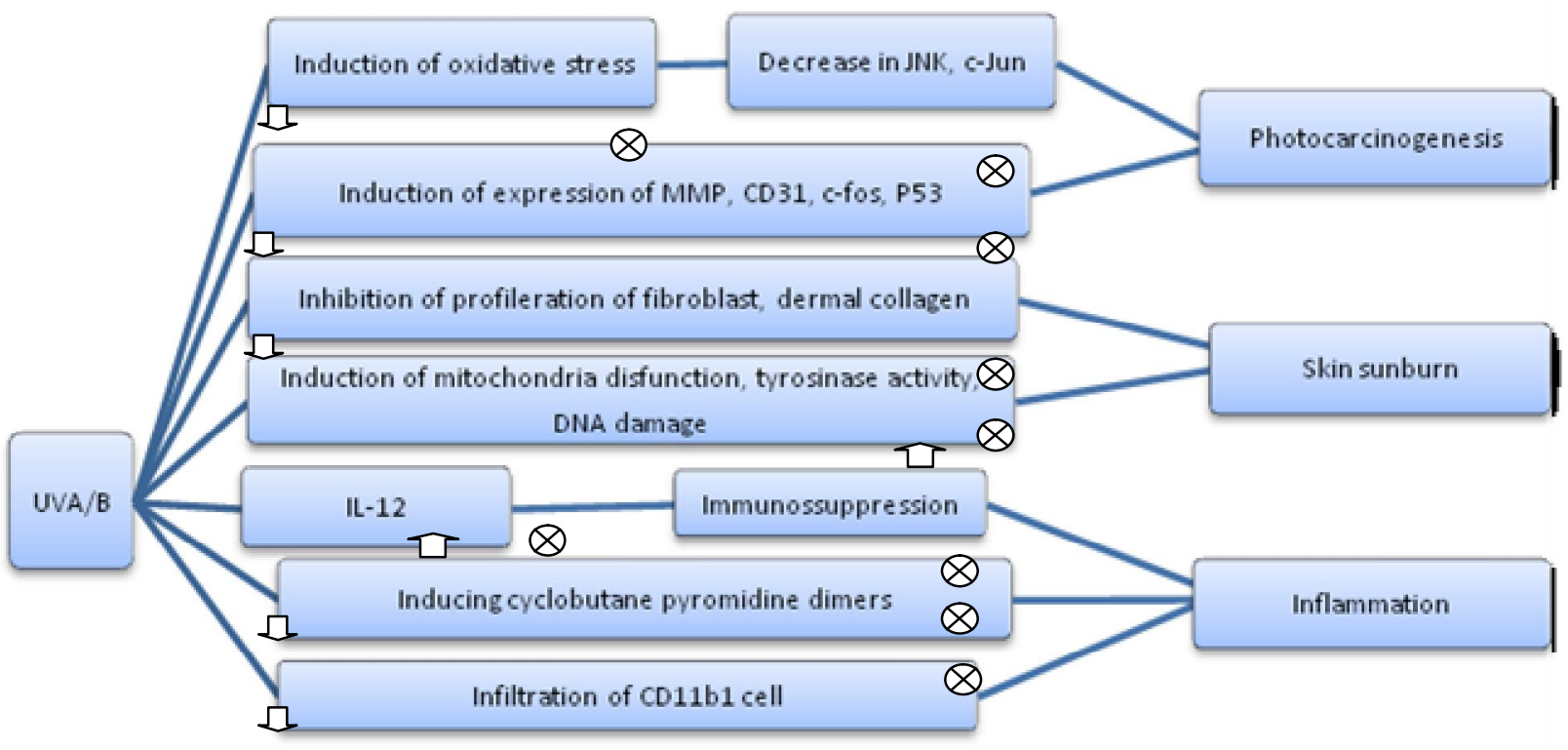

Figure 1: Photoprotective effects of tea extracts against ultraviolet $A / B$ radiation

$\uparrow=$ up-regulation by tea; $\downarrow$ = down-regulation by tea; : Inhibition by tea.

JNK = c-Jun NH2-terminal kinase; $c$-Jun = a protein encoded by the JUN gene; MMP = matrix metalloproteinases; $C D 31=$ cluster of differentiation $31 ; c$-fos $=$ a proto-oncogene that is the human homolog of the retroviral oncogene v-fos; P53 = tumor protein 53.

antiphotocarcinogenesis, reduction of skin sunburn and decrease in inflammation (Figure 1).

\section{ACKNOWLEDGMENT}

This work was supported by National Key Technology R\&D Program in the 12th Five Year Plan of China (Project no. 2012BAD36B06-2).

\section{CONFLICT OF INTEREST}

The authors declare no conflict of interest in this paper.

\section{REFERENCES}

1. Ablett E, Whiteman DC, Boyle GM, Green AC, Parsons $P G$. Induction of metallothionein in human skin by routine exposure to sunlight: Evidence for a systemic 
response and enhanced induction at certain body sites. J. Invest. Dermatol. 2003; 120: 318-324.

2. Kim SH. Dyeing Characteristics and UV protection property of green tea dyed cotton fabrics-Focusing on the effect of chitosan mordanting condition. Fiber Polym 2006; 7: 255-261.

3 Reinert G, Fuso F, Hilfiker R, Schmidt E. UV-protecting properties of textile fabrics and their improvement. Textile Chemist and Colorist 1997; 29: 36-43.

4. Wang ZY, Agarwal R, Bickers DR, Mukhtar H. Protection against ultraviolet $B \quad$ radiation-induced photocarcinogenesis in hairless mice by green tea polyphenols. Carcinogenesis 1991; 12: 1527-1530.

5 Record IR, Dreosti IE. Protection by tea against UV-A + Binduced skin cancers in hairless mice. Nutr Cancer 1998; 32: 71-75.

6. Record IR, Dreosti IE. Protection by black tea and green tea against UVB and UVA+B induced skin cancer in hairless mice. Mutat Res 1998; 422: 191-199.

7. Osanai K, Landis-Piwowar KR, Dou OP, Chan TH. A para-amino substituent on the $D$-ring of green tea polyphenol epigallocatechin-3-gallate as a novel proteasome inhibitor and cancer cell apoptosis inducer. Bioorg Med Chem 2007; 15: 5076-5082.

8 Mantena SK, Meeran SM, Elmets CA, Katiya SK. Orally administered green tea polyphenols prevent ultraviolet radiation-induced skin cancer in mice through activation of cytotoxic $t$ cells and inhibition of angiogenesis in tumors. Nutr Cancer 2005; 135:2871-2877.

9. Tobi SE, gilbert M, Paul N, Mcmillan TJ. The green tea polyphenol, epigallocatechin-3-gallate, protects against the oxidative cellular and genotoxic damage of UVA radiation. Intl J Cancer 2002; 102: 439-444.

10. Zhao JF, Zhang $Y J$, Jin $X H$, Athar $M$, Santella $R M$, Bickers DR, Wang DR. Green tea protects against psoralen plus altraviolet A-induced photochemical damage to skin. J Invest Dermatol 1999; 113: 10701075

11. Kaur $C D$, Saraf $S$. photochemoprtective activity of alcoholic extract of Camellia sinensis. Intl. J. Pharmacol. 2011; 7: 400-404.

12. Kim SY, Kim DS, Kwon SB, Park ES, Huh CH, Young SW, Kim SW, Park KC. Protective effects of EGCG on UVB-induced damage in living skin equivalents. Arch Pharm Res 2005; 28: 784-790.

13. Wu LY, Zheng XQ, Lu JL, Liang YR. Protective effect of green tea polyphenols against ultraviolet $B$-induced damage to HaCaT cells. Hum. Cell, 2009; 22: 18-24.

14. $X u J Y, W u L Y$, Zheng $X Q, L u J L, W u M Y$, Liang $Y R$. Green tea polyphenols attenuating ultraviolet $B$ induced damage to human retinal pigment epithelia cells in vitro. Invest Ophth Vis Sci 2010; 51: 66656670 .

15. Chiu AE, Chan JL, Kern, DG, Kohler S, Rehmus WE, Kimball $A B$. Double-blinded, placebo-controllecl tria of green tea extracts in the clinical and histologic appearance of photoageing skin. Dermatol Surg 2005; 31: 855-859.

16. Camouse MM, Domingo DS, Swain FR, Conrad EP, Matsui MS, Maes D, Declercq L, Cooper KD, Stevens SR, Baron ED. Topical application of green and white tea extracts provides protection from solarsimulated ultraviolet light in human skin. Exp Dermatol 2009; 18: 522-526.

17. Dal-Belo SE, Gaspar LR, Campos PMBGM. Photoprotective effects of topical formulations containing a combination of ginkgo biloba and green tea extracts. Phytother Res 2011; 25: 1854-1860.

18. El-Salamouny S, Ranwala $D$, Shapiro $M$, Shepard $B M$, Farrar RR. Tea, coffee, and cocoa as ultraviolet radiation protectants for the beet armyworm nucleopolyhedrovirus. J. Econ. Entomol.2009; 102: 1767-1773.
19. Wei X, Liu Y, Xiao J, Wang Y. Protective effects of tea polysaccharides and polyphenols on skin. J Agric Food Chem 2009; 57: 7757-7762.

20. Sevin A, Oztas $P$, Senen D, Han U, Karaman C, Tarimci $N$, Kartal M, Erdogan B. Effects of polyphenols on skin damage due to ultraviolet $A$ rays:an experimental study on rats. J Euro Acad Dermatol Venereol 2007; 21: 650-656.

21. Kim J, Hwang JS, Cho YK, Han Y, Jeon YJ, Yang KH. Protective effects of (-)-epigallocatechin-3-gallate on UVA and UVB-induced skin damage. Skin Pharmacol. Appl. Skin Physiol. 2001; 14: 11-19.

22. Elmets $C A$, Singh D, Tubesing $K$, Matsui M, Katiyar S, Mukhtar H. Cutaneous photoprotection from ultraviolet injury by green tea polyphenols. J Am Acad Dermatol 2001; 44: 425-32.

23. Katiyar SK, Bergamo BM, Vyalil PK, Elmets CA. Green tea polyphenols: DNA photodamage and photoimmunology. J Photochem Photobiol B: Biol 2001; 65: 109-114.

24. Katiyar SK, Elmerts CA, Agarwal $R$, Mukhtar $H$. Protection against ultraviolet- $b$ radiation-induced local and systemic suppression of contact hypersensitivity and edema responses in $\mathrm{C} 3 \mathrm{H} / \mathrm{HeN}$ mice by green tea polyphenols. Photochem. Photobiol. 1995; 62: 855-861.

25. Katiyar S, Elmets CA, Katiyar SK. Prevention of ultraviolet radiation-induced immunosuppression by (-)-epigallocatechin-3-gallate in mice is mediated through interleukin12-dependent DNA repair. Clin Cancer Res 2006; 12: 2272-2280.

26. Katiyar SK, Challa A, McCormick TS, Cooper KD, Mukhtar $H$. Prevention of UVB-induced immunosuppression in mice by the green tea polyphenol (-)epigallocatechin-3-gallate may be associated with alterations in IL-10 and IL-12 production. Carcinogenesis 1999; 20: 2117-2127.

27. Katiyar SK, Perez A, Mukhtar H. Green Tea polyphenol treatment to human skin prevents formation of ultraviolet light B-induced pyrimidine dimers in DNA. Clin Cancer Res 2000; 6: 3864-3869.

28. Schwarz A, Maeda, A, Gan D, Mammone T, Matsui MS, Schwarz T. Green tea phenol extracts reduce UVBinduced DNA damage in human cells via interleukin12. Photochem. Photobiol. 2008, 84, 350-355.

29. Katiyar SK. Green tea prevents non-melanoma skin cancer by enhancing DNA repair. Arch Biochem Biophy 2011; 508: 152-158.

30. Morley N, Clifford T, Salter L, Campbell S, Gould D, Curnow $A$. The green tea polyphenol (-)epigallocatechin gallate and green tea can protect human cellular DNA from ultraviolet and visible radiation-induced damage. Photodermatol. Photoimmunol Photomed 2005; 21:15-22.

31. Wölfle $U$, Esser PR, Simon-Haarhaus B, Martin SF. UVB-induced DNA damage, generation of reactive oxygen species, and inflammation are effectively attenuated by the flavonoid luteolin in vitro and in vivo. Free Radic. Biol. Med. 2011; 50: 1081-1093.

32. $F u Y C$, Jin XP. Ultraviolet radiation and reactive oxygen generation as inducers of keratinocyte apoptosis: protective role of tea polyphenols. J Toxico Environ Health, Part A 2000; 61:177-188.

33. Hong YH, Jung EY, Shin KS, Kim TY, Yu KW, Chang UJ, Suh $H$.. Photoprotective effects of a formulation containing tannase-converted green tea extract against UVB-induced oxidative stress in hairless mice. Appl Biochem Biotechnol 2012; 166: 165-175.

34. Jung $M Y$, Jung $M D, W u J W$, Choi DS. Effects of catechins and green tea extract on the photosensitized singlet oxygen oxidation of linoleic acid in a model system as compared with $\alpha$ tocopherol. Food Sci Biotechnol 2011; 20: 725-733.

35. Cavalier JF, Burton M, Dussart F, Marchand C, Rees JF, Marchand-Brynaert J. Catechol derivatives of 
aminopyrazine and cell protection against UVBinduced mortality. Bioorg Med Chem 2001; 9:10371044.

36. Lee $\mathrm{JH}$, Chung $\mathrm{JH}$, Cho $\mathrm{KH}$. The effects of epigallocatechin-3-gallate on extracellular matrix metabolism. J Dermatol Sci 2005; 40: 195-204.

37. Jagdeo J, Brody N. Complementary antioxidant function of caffeine and green tea polyphenols in normal human skin fibroblasts. J. Drugs Dermatol. 2011; 10 : 753-761.

38. Katiyar SK, Matsui MS, Elmets CA, Mukhtar $H$. Polyphenolic antioxidant (-)-epigallocatechin-3gallate from green tea reduces UVB-induced inflammatory responses and infiltration of leukocytes in human skin. Photochem Photobiol 1999; 69:148-1 53.

39. Jeon SE, Choi-Kwon S, Park KA, Lee HJ, Park MS, Lee JH, Kwon SB, Park KC. Dietary supplementation of (+)-catechin protects against UVB-induced skin damage by modulating antioxidant enzyme activities. Photodermatol Photoimmunol Photomed 2003; 19 : 235-241.

40. Katiyar SK, Afaq F, Perez A, Mukhtar H. Green tea polyphenol (-)-epigallocatechin-3-gallate treatment of human skin inhibits ultraviolet radiation-induced oxidative stress. Carcinogenesis 2001; 22: 287-294.

41. Cao G, Chen M, Song Q, Liu Y, Xie L, Han Y, Liu Z, Ji $Y$, Jiang $Q$. EGCG protects against UVB-induced apoptosis via oxidative stress and the JNK1/C-Jun pathway in ARPE19 cells. Mol Med Report 2012; 5 . 54-59.

42. Huang CC, Wu WB, Fang JY, Chiang $H S$, Chen $B H$, Chen YT, Hung CF. (-)-Epicatechin-3-gallate, a green tea polyphenol is a potent agent against UVBinduced damage in $\mathrm{HaCaT}$ keratinocytes. Molecules 2007; 12:1845-1858.

43. Srivastava RC, Husain MM, Hasan SK, Athar M. Green tea polyphenols and tannic acid act as potent inhibitors of phorbol ester-induced nitric oxide generation in rat hepatocytes independent of their antioxidant properties. Cancer Lett 2000; 153: 1-5.

44. Luo $D$, Min $W, W u$ D, Xu Y, Miao $X$. Effect of epigallocatechingallate on ultraviolet $B$-induced photo-damage in keratinocyte cell line. Am J Chin Med 2006; 34: 911-922.

45. Song $X Z, B i Z G, X u$ AE. Green tea polyphenol epigallocatechin-3-gallate inhibits the expression of nitric oxide synthase and generation of nitric oxide induced by ultraviolet $\mathrm{B}$ in $\mathrm{HaCaT}$ cells. Chin Med $\mathrm{J}$ 2006; 119: 282-287
47. Li YH, Wu Y, Wei HC, Xu YY, Jia LL, Chen J, Yang XS, Dong $\mathrm{GH}$, Gao $X H$, Chen $H D$. Protective effects of green tea extracts on photoageing and photommunosuppression. Skin Res Technol 2009; 15: 338-345.

48. Wu WB, Chiang HS, Fang JY, Chen SK, Huang CC, Hung CF. (+)-Catechin prevents ultraviolet B-induced human keratinocyte death via inhibition of JNK phosphorylation. Life Sci 2006; 79:801-807.

49. Afaq F, Adhami VM, Ahmad N, Mukhtar H. Inhibition of ultraviolet B-mediated activation of nuclear factor $j B$ in normal human epidermal keratinocytes by green tea constituent (-)-epigallocatechin-3-gallate. Oncogene 2003; 22: 1035-1044.

50. Lee $X Z$, Liang YR, Chen $H$, Lu JL, Liang HL, Huang FP, Mamati EG. Alleviation of UV-B stress in Arabidopsis using tea catechins. Afri J Biotechnol 2008; 7: 41114115.

51. Sharma VK, Bhattacharya A, Kumar A, Sharma HK. Health benefits of tea consumption. Trop J Pharm Res 2007; 6: 785-792.

52. Vayalil PK, Elmets CA and Katiyar SK. Treatment of green tea polyphenols in hydrophilic cream prevents UVB-induced oxidation of lipids and proteins, depletion of antioxidant enzymes and phosphorylation of MAPK proteins in SKH-1 hairless mouse skin. Carcinogenesis 2003; 24: 927-936.

53. Vermaak I, Viljoen AM, Hamman JH, Vuuren SFV. Effect of simulated gastrointestinal conditions and epithelial transport on extracts of green tea and sage. Phytochemistry Letters, 2009; 2: 166-170.

54. Chow HHS, Cai Y, Hakim IA, Crowell JA, Shahi F, Brooks CA, Dorr RT, Hara $Y$, Alberts DS. Pharmacokinetics and safety of green tea polyphenols after multiple-dose administration of epigallocatechin gallate and Polyphenon $E$ in healthy individuals. Clin Cancer Res 2003; 9: 3312-3319.

55. Ye JH, Li NN, Liang HL, Dong JJ, Lu JL, Zheng XQ, Liang YR. Determination of cyclic oligomers residues in tea catechins isolated by polyamide-6 column. J Med Plants Res 2011; 5: 2848-2856.

56. Lu YP, Lou YR, Li XH, Xie JG, Lin Y, Shih WJ, Conney $\mathrm{AH}$. Stimulatory effect of topical application of caffeine on UVB-induced apoptosis in mouse skin. Oncol Res 2001; 13: 61-70.

57. Wu J, Chen S, Ge S, Miao J, Li J, Zhang Q. Preparation, properties and antioxidant activity of an active film from silver carp (Hypophthalmichthys molitrix) skin gelatin incorporated with green tea extract. Food Hydrocoll 2013; 32: 42-51. 